\title{
Refusal Strategies Used by American Speakers and Indonesian Learners of English
}

\author{
Sartika $^{1}$, Endang Fauziati ${ }^{2}$, Sri Marmanto ${ }^{3}$, Iwan Jazadi ${ }^{4}$ \\ STKIP Paracendekia NW Sumbawa ${ }^{1,4}$, Indonesia; Universitas Sebelas Maret ${ }^{2,3}$, Indonesia \\ Correspondence: Sartika, STKIP Paracendekia NW Sumbawa, Indonesia, e-mail : tikaika1692@gmail.com \\ Submitted: April 02, 2020 \\ DOI: $10.29408 /$ veles.v4i1.2006 \\ Revised: April 20, $2020 \quad$ Accepted: April 24, 2020 \\ URL: http://dx.doi.org/10.29408/veles.v4i1.2006
}

\begin{abstract}
This article analyses refusal strategies applied by American speakers of English and Indonesian students of English as a foreign language. There were 21 subjects taking part in the study. Being descriptive qualitative, the research used discourse completion test and interview as the instruments of data collection and Miles and Huberman's flowchart as the tool to analyze the data. To be trustworthy, the data were triangulated through different sources, member checks and external check. The results indicate that both categories of subjects applied fourteen strategies to refuse, i.e. simply saying no, telling inability, avoiding, using hedges, making excuses, wishing, stating an option, promising to accept in the future, regretting, accepting but functioning as refusing, conditioning as past acceptance, gratitude/appreciation, pause fillers and statement of positive feeling/opinion; (2) some similarities and differences of strategies were found being used by both groups. Eleven strategies were found to be similar, namely, simply saying no, telling inability, delaying, making excuse, stating an option, regretting, wishing, lacking enthusiasm, gratitude/appreciation, pause fillers and statement of positive feeling. Meanwhile, the different refusal strategies used by those groups were hedging, promising to accept in the future and conditioning as past acceptance.
\end{abstract}

Keywords: Refusal strategies, EFL learners, pragmatics

\section{Introduction}

The pragmatic competence is crucial for language learners. Their ability in using language properly assists them to avoid miscommunication when they converse with the native speaker of the language. Thomas (1983, p. 97) mentions that linguistic errors just indicate that speakers are less proficient in language. Meanwhile, pragmatic failure leads to misunderstanding which may indicate that the speaker is rude, dishonest or unfriendly and even impolite if the listeners who come from another culture cannot understand some certain culture norms from the speaker. It may be assumed that the native speakers of certain language will tolerate if the language learners 
make some error in grammar or pronunciation as natural problem but they cannot accept if that happen in level of pragmatics. One of the main sources of pragmatic failure is negative pragmatic transfer in which language learners use native language pragmatic features that lead to an inappropriate form in the target language and hence miscommunication occurs (Sahragard \& Javarmandi, 2011, p. 182).

Pragmatic transfer has been studied by some researchers as the evidence of L2 speech performance. One of them is Beebe, Takahashi and Uliss-Weltz (1990) cited in Wannaruk (2008, p. 319) who conducted a study related to pragmatic transfer in refusal made by Japanese learners of English. One of ways to analyze the pragmatic competence of language learners is through speech act. Austin (1962) defines speech act as a set of utterance by which people perform a specific function such as apologizing, complaining, requesting, refusing, complimenting or thanking. Refusal speech act is one of the crucial issues in pragmatics compared to other speech acts because it relates to how to reject someone's intention and deals with face-saving activities. Besides, refusal is quite sensitive to some social variables such as gender, age, the level of education, power and social distance (Felix-Brasdefer, 2006, p. 160). Therefore, a speaker must be careful in performing refusal to minimize threat to the hearer's face.

Performing refusal is tricky even by a native language speaker and it becomes more difficult when it is performed by EFL learners. As stated by Al-Kahtani (2005, p. 37), "saying no is difficult for non-native speaker of a language". It is affected by cultural differences between that of the language learners and the target language. This condition is also faced by graduate students in Indonesia. They still bring their L1 knowledge in English refusal. It can be compared to the following conversation gained from a pilot study.

a. English Native speaker of America

You are a professor in Sebelas Maret University. One day, you are called and invited to come and give lecture in Indonesian University. Your Dean suggests you to fulfill the invitation but you are very busy and have to decline the invitation.

Your Dean : It is a great honor for our faculty that one of our professors is invited to give lecture in Indonesian University. I hope you will fulfill their invitation and make us proud of you.

You : I am sorry but I must decline, I am extremely busy at that time and already have a prior commitment. [regret + direct refusal strategy + reason]

\section{b. Indonesian EFL learner}

You are a professor in Sebelas Maret University. One day, you are called and invited to come and give lecture in Indonesian University. Your Dean suggests you to fulfill the invitation but you are very busy and have to decline the invitation.

Your Dean: It is a great honor for our faculty that one of our professors is invited to give lecture in Indonesian University. I hope you will fulfill their invitation and make us proud of you.

You : I'd love to sir but honestly I have another appointment at the same time. If you can delay it a day after, I will go there. [positive opinion + disability + future statement] 
Both of them face the same situation but they give different response. The native speaker refuses suggestion from one who has higher level status by expressing [regret + direct refusal strategy + reason]. Meanwhile, EFL learner refuses by showing her/his [positive opinion + disability + reason + future statement]. However, the most significant different between them is the use of addressee form "sir" from Indonesian EFL learner which does not find in American English native speaker utterance.

In Indonesian culture, the addresses form like "sir" is applied to show respect and politeness to the one who has higher social status. Besides, he performs indirect speech act to prove his politeness in order to save the speaker's face. In contrast, in American culture, it is quite rare to call someone "sir" although he has higher social status because they are normally called by his name. However, calling someone who has higher social status by his name is very impolite in Indonesian culture.

In addition, many researchers (e.g., Wijayanto, 2013; Chojimah, 2015; Ilmiani, 2016) have conducted study about refusal strategies. Generally, the previous studies focus on finding the refusal strategies that are commonly used by a single community like Indonesian EFL learners in a university or a study conducted by comparing native speakers of Indonesia and native English speakers. However, a few studies investigate refusal strategies used by Indonesian EFL learners and native English speakers. For this reason, this study tries to fill the gap by conducting a study about refusal strategies For this reason, this study tries to fill the gap by conducting a study about refusal strategies between "American English native speakers" (AENS) and "Indonesia EFL learners" (IEL). This research is guided by the following questions: (1) what strategies to refuse used by American speakers and Indonesia learners of English? and (2) what are similarities and differences of strategies for refusing employed by both groups? The study aims to identify the types of refusal strategies used by AENS and IEL, as well as the similarities and differences of refusal strategies used by AENS and IEL.

\section{Method}

This research is descriptive qualitative research in which the researchers focused on collecting data, analyzing data, interpreting them and making conclusion. Bagdan and Taylor (in Moleong, 1990, p.3) define 'qualitative methodology' as research procedure producing descriptive data in the form of people's written and spoken words and their behavior which can be observed Moleong (p.6) also states that in descriptive method, the collected data is in form of words, picture and not number. Furthermore, the data in this study will compare two kinds' data from the American speakers and Indonesian learners of English.

\subsection{Participants}

The participants were selected using a purposive sampling technique. This means that some requirements were made to adjust with the phenomena under study. The requirements for the American English speakers were that they were native English speakers who pursued a Master program at Ohio University. The requirements for Indonesian learners of English were that they had intermediate level mastery of TOEFL and were the students of Master of English Education 
Program at the Sebelas Maret University. Thus, twenty participants involved in this study were divided into 10 American speakers (AENS) and 10 Indonesian learners (IEL).

\subsection{Data Collection}

\subsubsection{Instrument of Collecting Data}

In this research, the writers collected the data through questionnaire using written discourse completion test (WDCT) and interview.

\subsubsection{Techniques for Collecting Data}

The first step of the present study procedure is gaining permission from Sebelas Maret University to conduct the study. After getting the permission, the WDCTs (that had been piloted with 2 participants of each group) were distributed to the participants who agreed to participate in this study. The purpose of piloting WDCTS was to check for any confusing term or description. Then, the participants selected randomly of each group to participate in the interview.

\subsection{Data Analysis}

After collecting all the data, the researchers analyzed them based on Miles and Huberman Model. Miles and Huberman (1984, p. 48) elaborate four types of analysis activity namely data collection, data reduction, data display and conclusion drawing/Verification.

\section{Results}

\subsection{Kinds of strategies for refusing applied by AENS and IEL}

Based on Beebe et al. (1990) taxonomy, the strategies can be categorized two kinds of strategies to refuse by AENS and IEL namely direct and indirect refusal strategies.

\section{a. Direct Strategy}

Direct strategy refers to refusals delivered in a direct manner with no mitigating formulas. It has some sub categories such as performative verb (I refuse) and non performative verb (no). Furthermore, based on the analysis of the DCT, both of AENS and IEL just apply performative verb in declining directly the interlocutors' request, offer, invitation and suggestion. Furthermore, performative verb has two branches namely direct no and negative willingness or inability.

\section{1) Direct No}

In 'direct no' strategy, refusals are shown by simply saying "no" without internal alteration. The word "No" is a direct way of refusal and it is frequently combined with other refusal strategies, except in few cases, when people are extremely direct.

Generally, in this study, AENS use direct no along with other indirect refusal strategies such as inability, excuse and gratitude to complete their utterances. Besides, they compose their utterances using three kinds of refusal strategies. The example of their utterance is stated below.

No, I have a friend on the way. Thank you [AENS/12/8]

Another side, IEL also unite direct no with other refusal strategies like inability, gratitude and excuse. They sometimes combine direct no with one or two other refusal strategies. It can be seen in the following example. 
No, thank. I can fix by myself [IEL/12/4]

2) Inability

This category includes some expressions which contain negative negations. Negation can be expressed by the negative particles "Not" or by using any word that semantically negate a proposition like 'I can't' or 'I do not think I can make it'. Occasionally, AENS simply use inability or combine it with other strategy for instance excuse, direct no, gratitude and statement of regret.

Thanks for the offer, but I can't. [AEN/6/4]

Meanwhile in IEL utterances, they use inability along with statement of regret, filler, hedging and statement of positive feeling.

I am afraid; I can't for this time because I have several further dated schedules which I cannot cancel. [IEL/5/2]

\section{b. Indirect Strategies}

Indirect strategies are verbal messages that disguise the speakers' needs. Basically, there are eleven branches of indirect refusal strategies and ten of them are utilized by AENS and IEL. Those strategies are avoidance, making excuses, wishing, stating an option, regretting, statement of alternative, statement of principle and promise of the future acceptance. The details of them are explained below.

1) Avoidance

In refusal strategies, avoidance may be expressed by mean of a verbal act (such as changing the subject, joking or hedging or by means of a non-verbal act (such as silent, hesitation, or physical departure). Furthermore, avoidance has two branches that are postponement and hedging.

Repeatedly, native English speakers utilize postponement with excuse. as the form of their avoidance. The postponement is stated at the beginning of the utterance and mingled with excuse. The details are mention as follow:

(1) I'll put that into consideration, but remember there is a value to my lectures [AENS/2/6]

Quite the reverse, postponement is rarely used by IEL in their utterance. The evidence shows that only one utterance that contains postponement refusal strategy can be found. Furthermore, unlike AENS that combine postponement with excuse, IEL articulate the postponement (I will try to think about it) with gratitude (thank you). It express in the following example:

I will try to think about it, thank you. [IEL/3/4]

\section{2) Hedging}

Hedging refers to pragmatic indicators that reduce the vigor of an expression. In this case, the purpose of hedging is to weaken the refusal utterance so it does not violate the speakers' face strongly. Moreover, hedging refusal strategies is only located at Non IEL' utterance. They combine hedging with excuse, statement of regret, in ability and statement of positive feeling. Below are utterances that unite hedging with those refusal strategies: 
That's sound interesting, but I guess I couldn't attend the next meeting since I am taking my mother to the airport. I will ask for the recording if possible, if you and they don't mind. [AENS/8/2]

\section{3) Excuse}

The respondent indirectly rejects the request by indicating some reasons, which may be general or specific. The purpose of a speaker uses excuse, reason or explanation is not for complying to the interlocutor but to refuse them indirectly. The excuse refusal strategy can be single-handedly stated or combined with direct or indirect refusal strategies. Those strategies are fillers, postponement, gratitude, statement of alternative, statement of regret, statement of positive opinion, inability, wish and direct no. The following examples are applied by IEL:

Thank you, but I am going to use a different printer [AENS/10/2]

Furthermore, IEL also use excuse in the same way as AENS. More frequently, they state a specific reason when they make refusals like they have importance meeting with the collage in that nigh or they use it for quite long during the completion of the assignment.

4) Wish

Wish is conducted by wishing that an interlocutor could do something for the requester wants. AENS manipulate wish with statement of regret, statement of alternative and excuse whereas IEL merely join it with excuse. The utterances produced by both of groups are stated below.

I wish I could, but I am busy on Sunday, May be next time? [AENS/9/5]

5) Statement of Alternative

Statement of alternative is a condition in which the speakers are looking for an alternative such as suggestion or offer to decline the hearer wants. Furthermore, AENS combine statement of alternative with filler, apologizing, stating an option, regretting and appreciation.

I am sorry, but I don't think I will be able to stay late due to conflict. Can you find someone else? [AENS/5/1]

In addition, IEL unite statement of alternative with filler, statement of agreement, inability, statement of positive feeling.

Hmm, but mom. I can't. Sometimes, telling about own personal experiences make me uncomfortable. Would you like to give another idea mom? [IEL/3/7]

6) Promise of Future Acceptance

In some conditions, the refusal may contain a promise that the requests will be accomplished at a later time, when there are favorable condition for its completion. Promise of the future acceptance may be stated alone or joined with refusal strategies such as statement of regret, statement of positive feeling and excuse like reveals below:

I am so sorry I really want to help you but I have an appointment that I can't cancel, I will help you another time. [IEL/5/9]

7) Statement of Regret

In this strategy, a speaker rejects the interlocutor's request by stating apology or regret. In order to soften his rejection, he will apply the words 'sorry' or 'regret' to show that he feels bad for unfulfilling the request. Besides, it commonly unites with other indirect refusal strategies 
such as inability and excuse. Furthermore, AENS combine statement of regret with direct no, inability, statement of regret and excuse.

No, I can't change my lecture. I'm sorry. [AENS/2/4]

Moreover, IEL also unite statement of regret with gratitude, statement of positive feeling, wish, hedging and excuse.

Thank you very much for your recommendation, but I am sorry sir. I am not interested in writing about that. [IEL/3/2]

8) Acceptance that functions as a refusal

a) Lack of Enthusiasm

Linguistically, lack of enthusiasm can be defined as a feeling of uninterested in particular subject or activity and apathy to be involved in it. Lack of enthusiasm applied by AENS comes together with other indirect refusal strategies like excuse and gratitude. The utterances from AENS are mentioned below:

(1) I am not really interested. Thank you though. [AENS/1/10]

Correspondingly, IEL join lack of enthusiasm with gratitude and inability. The last two example below illustrate that the position of lack of enthusiasm are at the beginning of the utterance such as I don't want to take his class and I don't really like the way professor $X$ teaching in his class. Those are followed by gratitude (thank you anyway for your suggestion) and inability (I will not take his class). Furthermore, in the first example, lack of enthusiasm (I don't have any interest in his class) is leaded by gratitude (Thanks for your suggestion).

Thanks for your suggestion but I don't have any interest in his class. [IEL/1/4]

9) Set Condition for Past Acceptance

With an assumed situation as a cause to refuse, the speaker relates the refusal to the context when the interlocutor had better made the request earlier. Set condition for past acceptance is only used by IEL. It merges with gratitude, statement of regret, excuse and inability. Furthermore, it is only covered one utterance and the complete sentence in the following.

Hello Wiranto, thanks for calling me. Regarding your invitation, I am really sorry that I cannot attend it owning to another previous agreement which I had made several days ago with another institution. I would probably afford it if I were free on the day you previously planned. [IEL/7/8]

The example of set condition for past acceptance utterance is I would probably afford it if I were free on the day you previously planned and it is preceded by gratitude (thanks for calling me), statement of regret (I am really sorry), inability (I cannot attend it owning to another previous agreement), and excuse (I had made several days ago with another institution).

\subsection{Similar and Different Strategies of Refusal}

After evaluating the refusal strategies used by both of AENS and IEL as stated in the previous section, it assists to answer the second questions about finding similarities and differences of refusal strategies between the two groups. To simplify, it is shown in Table 1. 
Table 1. Similarities and different refusal strategies used by AENS and IEL

\begin{tabular}{|c|c|c|}
\hline Name of group & Similar types of refusal strategies & Different types of refusal strategies \\
\hline AENS & $\begin{array}{l}\text { Simply saying no, telling inability, } \\
\text { delaying, apologizing, stating an } \\
\text { option, regret, wishing, lacking } \\
\text { enthusiasm, gratitude/appreciation, } \\
\text { pause fillers and statement of positive } \\
\text { feeling }\end{array}$ & \\
\hline IEL & $\begin{array}{l}\text { Simply saying no, telling inability, } \\
\text { delaying, apologizing, stating an } \\
\text { option, regret, wishing, lacking } \\
\text { enthusiasm, gratitude/appreciation, } \\
\text { pause fillers and statement of positive } \\
\text { feeling }\end{array}$ & $\begin{array}{l}\text { Using hedges, promising to accept in } \\
\text { the future, conditioning to accept in the } \\
\text { past }\end{array}$ \\
\hline
\end{tabular}

\section{Discussion}

\subsection{Kinds of Strategies to Refuse by AENS and IEL}

The findings of types of refusal strategies in this research show that the participants taken from AENS and IEL employ two broad categorized of refusal strategies that are direct and indirect. Those refusal strategies applied in this study have eleven subdivision i.e. simply saying no, telling inability, avoiding, using hedges, making excuses, wishing, stating an option, promising to accept in the future, regretting, accepting but functioning as to refuse and conditioning to accept in the past. Among those refusal strategies, IEL use eleven refusal strategies while AENS apply eight of them.

This finding agree with Chojimah (2015) that covers Indonesian University Students apply ten refusal strategies in their utterances and those are also classified into direct and indirect refusal strategies. Besides, it also confirms about the utilization of redressive expression in their utterances. Direct strategies compose of performative verb, direct no and inability. Indirect strategies have some braches namely criticizing, presenting other agenda, showing a reference and stating self-limitation and statement of regret. Meanwhile, redressive consists of gratitude and statement of positive feeling. The similar number of refusal strategies applying between the two groups may be caused by the similar setting of the study that is in formal setting. Nguyen (2006, p. 13) states that there are twelve socio-cultural factors that affect directness and indirectness of utterances. One of those factors is setting.

\subsection{Differences and Similarities of I Strategies to Refuse by AENS and IEL}

By applying direct and indirect refusal strategies, it is uncovered that eleven subdivisions of refusal strategies utilized by both of AENS and IEL. They share eight refusal strategies (direct no, inability, postponement, excuse, wish, statement of alternative and statement of regret and lack of enthusiasm) and differ in three strategies (hedging, promise of future acceptance and set condition for past acceptance). This condition corresponds to Hosseini and Talebinez had study 
(2014) that mentions that native and non-native English speakers mostly follow same refusal strategies but in some cases they differ.

Stating direct refusal strategies may considers as impolite and both of groups realize about this phenomenon. It can be seen from the utilization of direct refusal strategies in their utterances that never use direct refusal strategies in one combination act. They join direct refusal strategies with others such as merging it with statement of regret (sorry), or gratitude (Thank you). The purpose of combining direct refusal with others is to minimize the cost of the interlocutors. It is supported by Lee (1983, p. 125) who state that "minimizing cost but maximizing benefit to others and maximizing cost but minimizing benefit to others. Moreover, IEL more repeatedly apply direct refusal strategies that AENS. This illustrates that direct refusal strategies do not prohibit in Indonesia utterances. It agree with Ilmiani (2016) that prove Indonesian EFL Students use direct no and inability in their refusal more frequently to refuse request and suggestion.

Furthermore, indirect refusal strategy is the foremost category of refusal strategies utilized by both of AENS and IEL. IEL utilize more indirect refusal strategies than AENS. This finding is supported by Chojimah (2015) that mentions indirect refusal strategy is the most favorable strategies of Indonesian students. Besides, indirect refusal strategies correlate with politeness that exists in Indonesian culture built from the Prinsip Saling Tenggang Rasa or the Principle of Mutual Consideration (PMC). It states that avoid using expressions to your interlocutors which you would not like to be addressed to you if you were in his/her shoes. Generally, the principle is similar to Brown and Levinson politeness principle.

In term of differences, hedging is only attained in IEL utterances. Hedging has a function to alleviate face threatening act of the refusal by giving a hint (like $I$ am not sure or I think) to the interlocutor before they decline the speakers' desire. It is supported by Kartomiharjo (1990) that giving hints is considered to be more polite than refusing by using 'no'. The utilization of hedging in IEL utterances correlate to one of Indonesian characteristics that tends to give long prolog before stating their refusals.

\section{Conclusion}

Based on the findings and discussion, the conclusion can be drawn. First, there are two broad classifications of strategies to refuse applied by American speakers and Indonesian learners of English, namely direct and indirect. Direct strategies has two subdivisions that are direct no and inability while indirect strategies consist of some branches, i.e. avoiding, hedging, making excuses, wishing, stating an option, promising to accept in the future and regretting, accepting but functioning as refusal and set of past acceptance. Second, in applying those strategies, it is some similarities and differences between AENS and IEL. For similarities, eleven strategies of refusal were committed by both groups such as simply saying no, telling inability, delaying, apologizing, stating an option, regretting, lacking enthusiasm, gratitude/appreciation, pause fillers and statement of positive feeling . Besides, different strategies of refusal between American speakers and Indonesian EFL learners are also uncovered (i.e., using hedges, promising to accept in the future, and conditioning to accept in the past). 


\section{References}

Al-Kahtani, S. A. (2005). Refusal Realization in Three Different Cultures: A Speech Act Theoritically-based Cross Cultural Study. Journal of King Saud University, 18(1), 35-37.

Austin, J. (1975). How to Do Things with words. Cambridge: Harvard University Press.

Beebe, L. M., Takahashi, T., \& Uliss-Weltz, R. (1990). Pragmatic transfer in ESL refusal. In developing communicative competence in as second language. New York: Newbury House.

Brasdefer, J. C. (2003). Declining an Invitation: A cross cultural studyof pragmatic strategies in American English and Latin American Spanish. Multilingua, 22(3), 225-255.

Chojimah , N. (2015). Refusal and Politeness Strategies in relation to Social Status: A Case of Face - Treatening Act Among. Theory and Practice in Language Studies, 5(5), 906-928.

Hosseni, H., \& Talebinezhad, M. R. (2014). A comparative study of the use of refusal strategies between Iranian EFL Learners and Native Speakers of English. International Journal of Language Learning and Applied Linguistics World, 5(2), 2289-3245.

Ilmiani , D. (2016). A compatison between refusal strategies in English made by Indonesian EFL Students and Thai EFL Students: an interlanguage study. Unpublish master's thesis. Master of Language Studies Post Graduate Program: Muhammadiyah University of Surakarta.

Miles, M., \& Huberman, A. M. (1994). Qualitative Data Analysis: A Source of New Methods . Baverly Hills: SAGE Publication Inc.

Moleong, J. (1990). Metodologi Penelitian Kualitatif. Bandung: Remaja Rosdakarya.

Nguyen. (2006). Cross-cultural pragmatics: Refusal of request by Australian ative Speakers of English and Vietnemese Learners of English . Unpublish dissertation. The Faculty of Arts : The University of Queensland.

Sahragard, R., \& Javanmardi, F. (2011). English Speech Act Realization of "Refusal"among Iranian EFL Learners. Cross-Cultural Communication, 7(2), 181-198.

Surakhmad. (1994). Pengantar Penelitian Ilmiah Dasar, Metode \& Teknik. Bandung : Tarnsito Press.

Wannaruk, A. (2008). Pragmatic Transfer in Thai EFL Refusal. RELC, 39(3), 318-337.

Wijayanto , A. (2013). The emergence of the Javanese sopan santun (politeness on refusal strategies used by Javanese Learners of English). The Internet Journal Language, Cultural and Society(36), 1-43. 